\title{
Role of transvaginal ultrasound in detection of endometrial changes in breast cancer patients under hormonal therapy
}

\author{
Waleed M. Hetta ${ }^{1 *} \mathbb{D}$, Amgad Samy', Marwa Romeih² and Aya Salah²
}

\begin{abstract}
Background: The aim of the study is to evaluate the role and efficacy of transvaginal ultrasound in detection of endometrial changes in breast cancer patients under hormonal therapy in correlation with histopathological results of endometrial biopsies. Fifty patients with breast cancer under tamoxifen were subjected to transvaginal ultrasonography, and the results are compared with histopathological results of endometrial biopsies from March 2018 to November 2018.

Results: Twenty-two patients (44\%) had normal regular endometrium, and twenty-eight patients (56\%) had abnormal ultrasonographic appearance with different types of pathology; there were 24 patients (85.7\%) with endometrial abnormality and 4 patients (14.3\%) with adnexal pathology. The twenty-four patients with endometrial abnormality were as follows: 10\% endometrial atrophy, 4\% endometrial carcinoma, 14\% endometrial hyperplasia, and $7 \%$ endometrial polyp with sensitivity of $92.9 \%$ and accuracy of $96 \%$ in comparison to histopathology results.

Conclusion: We found in our study that transvaginal ultrasonography is a sensitive and rather specific method to evaluate the endometrial lesions, so we concluded that it is a necessary screening tool for detection of endometrial abnormalities in breast cancer patients under hormonal therapy.
\end{abstract}

Keywords: Transvaginal ultrasound, Endometrial changes, Breast cancer, Hormonal therapy

\section{Background}

Breast cancer is the second leading cause of cancer mortality among women, after lung cancer. According to the American Cancer Society, approximately 1.3 million women worldwide are diagnosed with breast cancer annually, and $>465,000$ women die of this disease [1].

Postoperative adjuvant systemic therapy prolongs survival in selected women with breast cancer and reduces the odds of death by $25 \%$ per year [1].

Since the early 1980s, tamoxifen has become the standard adjuvant therapy for patients with breast cancer, reducing the risk for a second case of contralateral primary breast cancer from 30 to $50 \%$ [2].

Tamoxifen is structurally related to diethylstilbestrol and clomiphene citrate. While acting as an

\footnotetext{
*Correspondence: waleed_hetta@yahoo.com

${ }^{1}$ Department of Radio-diagnosis, Faculty of Medicine, Ain Shams University,

Ramsis St., Abbasia, Cairo, Egypt

Full list of author information is available at the end of the article
}

estrogen antagonist in the breast, it has estrogen agonist activity in other tissues, increasing thickness of the vaginal epithelium, reducing serum cholesterol levels, and preserving bone density in postmenopausal women [2].

Laboratory studies have demonstrated estrogen-like effects on steroid hormone receptors in endometrium and growth-promoting effects on endometrial carcinoma cells. During the past decade, several reports have cited an increased incidence of endometrial abnormality, ranging from polyps to cancer, in women receiving tamoxifen [2].

Although tamoxifen has been implicated in the development of endometrial cancer, many epidemiologic and genetic risk factors that predispose women to breast cancer can also increase the overall risk for developing gynecologic cancer [2].

Transvaginal ultrasound is a highly reliable method for detecting endometrial cancer in patients with 
postmenopausal bleeding. It may indicate the type of abnormality seen within the endometrium, for example, endometrial hyperplasia, polyps, or carcinoma [3].

Sampling of the endometrium must be performed if there is diffuse or focal thickening of the endometrium. Pathological confirmation of the histology is needed in all cases, as the ultrasound appearances overlap considerably [3].

Transvaginal ultrasound may also identify ovarian pathology, including polycystic ovaries in younger women and ovarian tumors secreting estrogens, causing abnormal vaginal bleeding [3].

Thus, we undertook this study to evaluate the effect of tamoxifen on endometrium in breast cancer patients and to know the correlation between ultrasonographic and histopathological findings.

The aim of the study is to evaluate the role and efficacy of transvaginal ultrasound in the detection of endometrial changes in breast cancer patients under hormonal therapy in correlation with histopathological results of endometrial biopsies.

\section{Patients and methods}

This is a cross-sectional prospective study which included 50 patients in a convenience sample. We analyzed the data from previous scans and current scan and correlate it with the results of histopathology. All US examinations were performed by senior radiologists at the Radiology Department of Helwan University Hospital during the period from March 2018 to November 2018 with study population according to the following criteria:

Inclusion criteria: known breast cancer patients under (tamoxifen) as a part of their treatment strategy.

Exclusion criteria: breast cancer patients not under hormonal therapy as well as virgin patients.

The study was approved by the local ethical committee, the whole procedure was explained to the patient, and we took an informed consent from them.

All patients in this study were subjected to the following:

\section{A. History}

1) Age

2) Family, Medical and surgical history.

3) Treatment of breast cancer (surgery, CTH, RTH)

4) Hormonal therapy, when did she start, for how long and finished or not?

5) History of recurrence or not?

6) Pre- or postmenopausal?
7) Did she underwent any endometrial biopsy and what was the result?

\section{B. Radiological examination}

Real-time ultrasound was performed using Toshiba Aplio 400 (Toshiba Medical Systems, Japan) and GE Logiq P5 (GE Healthcare, Milwaukee, WI) ultrasound machines with the vaginal transducer $(5-10 \mathrm{MHz})$.

This examination is for the uterus for size and axes, endometrium for thickness, subendometrial halo preserved or not, cystic changes, homogeneity, myometrium, cervix and cervical canal, ovaries, any adnexal abnormality, and fluid in cul-de-sac.

For the examination technique, the whole procedure was explained to the patient, and then, a verbal consent was taken.

A look by transabdominal US with full bladder is taken before starting transvaginal scan because it had a large scale of view to assess the overall appearance of the uterus and adnexa.

The transvaginal scan is done at the lithotomy position, with an empty bladder, and the pelvis is slightly elevated.

We ensured that patient is comfortably lying during the whole scan time. The patient's dignity must be maintained by appropriately covering her adequately at all times:

- First, we imaged the uterus including the fundus, body in longitudinal and transverse views, identified its axes and took its measurements.

- Then, we imaged the cervix and lower uterine segment and took the length of the cervix to know its proportion to uterine body.

- We checked the echo pattern of the myometrium and its regularity, and we searched for any focal lesion.

- For any myometrial focal lesion that could be detected, we should identify its site, size, shape, echo pattern, consistency, borders, regularity, vascularity, and relations; the presence of calcifications; and if there were any pressure effects.

- Then, we measured the thickness of endometrium, its regularity, and echo pattern.

- The endometrium was measured in the long axis or sagittal plane. The measurement is of the thickest echogenic area from one basal endometrial interface across the endometrial canal to the other basal surface. Care should be taken not to include the hypoechoic myometrium in this measurement as this represents the inner zone of myometrium. 
- We evaluated the ovaries and adnexa in both longitudinal and transverse views.

- The ovaries were evaluated for site, size, shape, echo pattern, follicles and presence of dominant one, any ovarian cyst, and mass.

- We evaluate the cul-de-sac for the presence of free or localized fluid, and whether it was clear or turbid.

- Clinical and ultrasound data were compared with the final histological diagnosis of the endometrium, which was obtained by $\mathrm{D} \& \mathrm{C}$, hysteroscopic resection for all patients.

\section{Statistical methods}

Data were collected, revised, coded, and entered to the Statistical Package for Social Science (IBM SPSS) version 23. The quantitative data were presented as mean, standard deviations, and ranges when their distribution found parametric. Also, qualitative variables were presented as number and percentages. The comparison between groups regarding qualitative data was done by using the chi-square test. The comparison between two independent groups with quantitative data and parametric distribution as done by using the independent $t$ test, while the comparison between more than two group was done by using the one-way ANOVA test.

The confidence interval was set to $95 \%$, and the margin of error accepted was set to $5 \%$. So, the following $p$ values were considered significant:

$p$ value $>0.05$ : non-significant $(\mathrm{NS})$

$p$ value $<0.05$ : significant $(\mathrm{S})$

$p$ value $<0.01$ : highly significant $(\mathrm{HS})$

\section{Results}

Prospective study was carried out on 50 patients known with breast carcinoma who came to the radiology department at Helwan University; their age ranged from 32 to 55 years old; their mean age was 44.90 years and standard deviation \pm 5.80 years. Twenty-two patients (44\%) were with positive family history to breast cancer. All patients done surgical treatment, received chemo/ radiotherapy and hormonal treatment (tamoxifen), and became menopause as a side effect of chemotherapy (Table 1).

The patients received tamoxifen therapy for a period ranging from 3 months up to 5 years with a mean duration of 2.31 years and standard deviation of \pm 1.36 years. All of the patients were examined by transvaginal ultrasonography (TVUS) as a routine follow-up; 9 patients (18\%) were complaining from abnormal vaginal bleeding with various degrees. By TVUS, endometrial thickness measurement was ranging from 3 to $30 \mathrm{~mm}$ with a mean
Table 1 Demographic data of the patients

\begin{tabular}{lll}
\hline & & No. $=50$ \\
\hline Age (years) & Mean \pm SD & $44.90 \pm 5.80$ \\
& Range & $32-55$ \\
Family history & Negative & $28(56.0 \%)$ \\
& Positive & $22(44.0 \%)$ \\
Postmenopause & Yes & $50(100.0 \%)$ \\
Surgery & MRM (modified radical mastectomy) & $27(54.0 \%)$ \\
& Lumpectomy & $22(44.0 \%)$ \\
& Lumpectomy then MRM & $1(2.0 \%)$ \\
\hline
\end{tabular}

of $10.22 \mathrm{~mm}$ and standard deviation of $\pm 5.76 \mathrm{~mm}$, with 10 patients (20\%) having irregular endometrium (Table 2).

Twenty-two patients (44\%) had smooth, regular endometrium with normal thickness and normal myometrial echogenicity with no focal lesion detected, as well as normal sonographic appearance of both ovaries.

Twenty-eight patients (56\%) had abnormal ultrasonographic appearance with different types of pathology; these abnormalities were detected either in endometrium or in adnexa.

There were 24 patients $(85.7 \%)$ with endometrial abnormality and 4 patients (14.3\%) with adnexal pathology.

In four patients with normal endometrium, we detected ovarian cysts either simple or complicated showing turbid content or fluid level (Fig. 1).

Twenty-four patients had endometrial abnormality with normal sonographic appearance of the myometrium and adnexa, those patients underwent D\&C and correlate the TVUS findings to the histopathology results, and the results were as follows: 5 cases with adenomyosis (10\%), 3 cases with endometrial atrophy (6\%), 2 cases with endometrial carcinoma (4\%), 7 cases with endometrial hyperplasia (14\%), and 7 cases with endometrial polyp (14\%).

Table 2 Representing distribution of patients according to the period of hormonal therapy, symptomatic, endometrial thickness, and regularity by TVUS

\begin{tabular}{lll}
\hline & & No. $=50$ \\
\hline Hormonal (year) & Mean \pm SD & $2.38 \pm 1.42$ \\
Symptomatic (vaginal bleeding) & Ro & $0.33-5$ \\
& Yes & $41(82.0 \%)$ \\
US-endometrial thickness $(\mathrm{mm})$ & Mean \pm SD & $9(18.0 \%)$ \\
& Range & $10.22 \pm 5.76$ \\
US-endometrial regularity & Irregular & $3-30$ \\
& Regular & $40(20.0 \%)$ \\
\hline
\end{tabular}




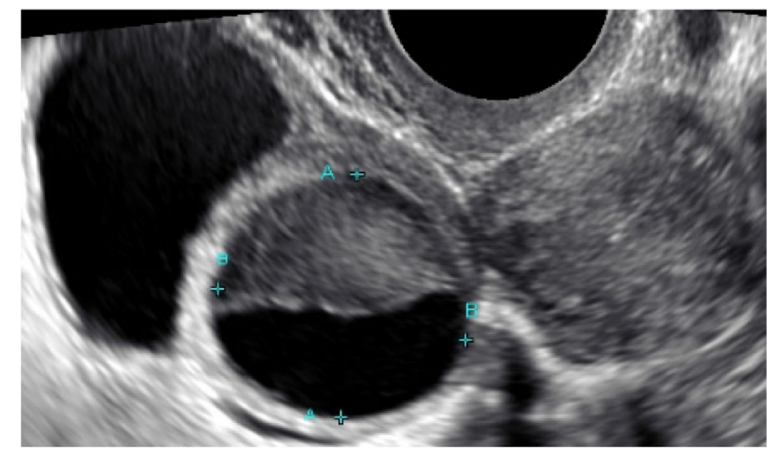

Fig. 1 TVUS showing adnexal cysts (simple and complicated)

In seven patients, we detected echogenic focal or diffuse homogenous endometrial thickening or mass which ranged from 13 to $17 \mathrm{~mm}$ showing internal variable sized well-defined cysts, regular border \pm vascular pedicle, and intracavitray lesion showing \pm surrounding anechoic area representing fluid or secretions inside uterine cavity; we suggested that they were endometrial polyp which are proven by the histopathology in them (Fig. 2).

In seven patients, we detected focal or diffuse echogenic endometrial thickening which ranged from 12.5 to $20 \mathrm{~mm}$ with regular border and well-defined endometrial-myometrial interface, preserving subendometrial halo, and may show internal variable sized well-defined cysts; heterogeneous or hypoechoic area were atypical; we suggested that they were endometrial hyperplasia which are proven by the histopathology in them (Fig. 3).

In five patients, we detected subendometrial echogenic nodules/linear striations that extend from the endometrium to the inner myometrium with bulky uterus and thickened endometrium which ranged from

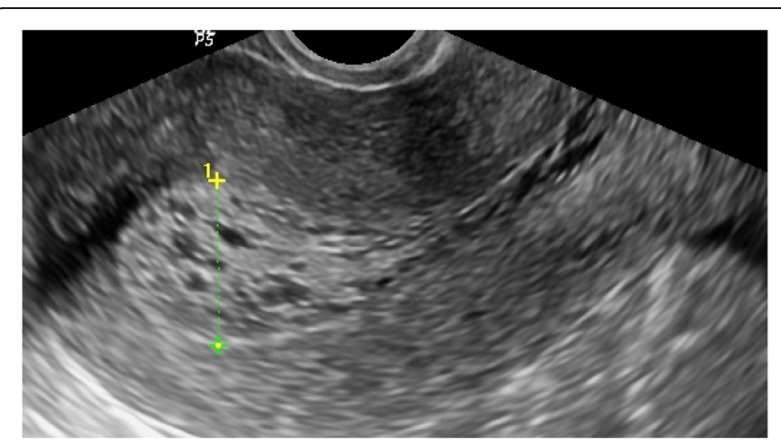

Fig. 3 Sagittal view by TVUS showing a thickened homogenous echogenic endometrium, measuring about $12.5 \mathrm{~mm}$ in maximal anteroposterior diameter $(A)$, with regular borders, preserving subendometrial halo and few variable sized cysts. Histopathology result of the endometrial biopsy was consistent with

endometrial hyperplasia

8.6 to $11 \mathrm{~mm}$; in most of them, it was irregular and heterogeneous, and all showed indistinct endometrial border and multiple hypoechoic cystic spaces, which are also seen in myometrium; we suggested that it was adenomyosis which was proven by the histopathology in them (Fig. 4).

Two patients had thin endometrium, 3 and $4 \mathrm{~mm}$, that was smooth and uniform and that had echogenic endometrial stripe; we suspected that they were endometrial atrophy, which is proven by the histopathology (Fig. 5). In another patient, we detected the presence of multiple hypoehoic areas representing variable sized cysts and heterogeneous thickened endometrium $14.7 \mathrm{~mm}$; we suggested it was endometrial carcinoma, but with histopathology, it was endometrial cystic atrophy (Fig. 6).

One patient had an ill-defined heterogeneous echogenic diffusely thickened endometrium $30 \mathrm{~mm}$ with loss

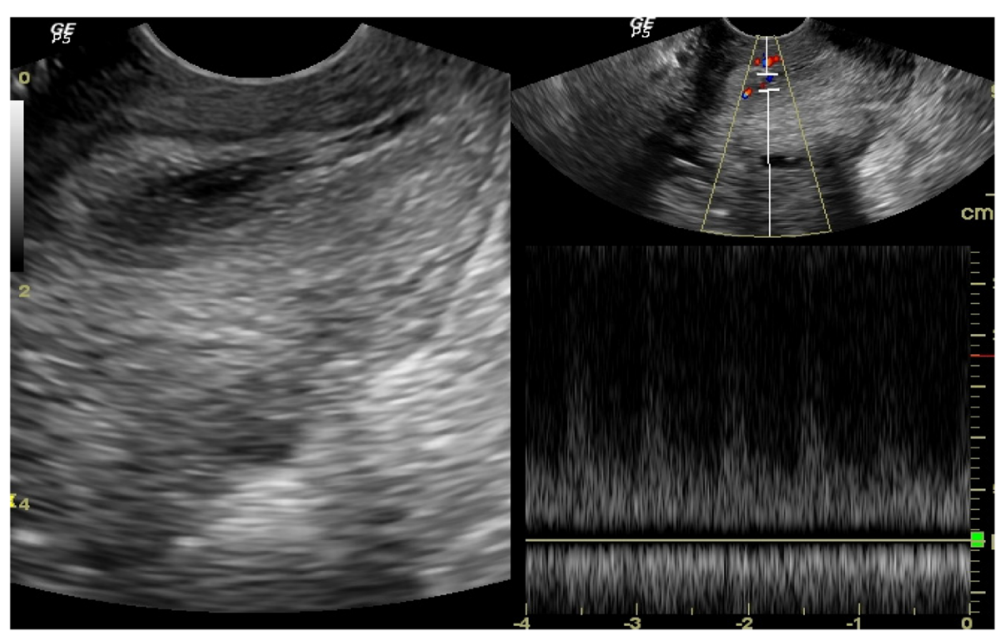

Fig. 2 Sagittal view by TVUS showing thickened echogenic endometrium and homogenous echo pattern measuring about $25 \times 16 \mathrm{~mm}$ (CC $x$ AP) with regular borders, preserving subendometrial halo and vascular pedicle. Histopathology analysis of the endometrial biopsy revealed endometrial polyp 


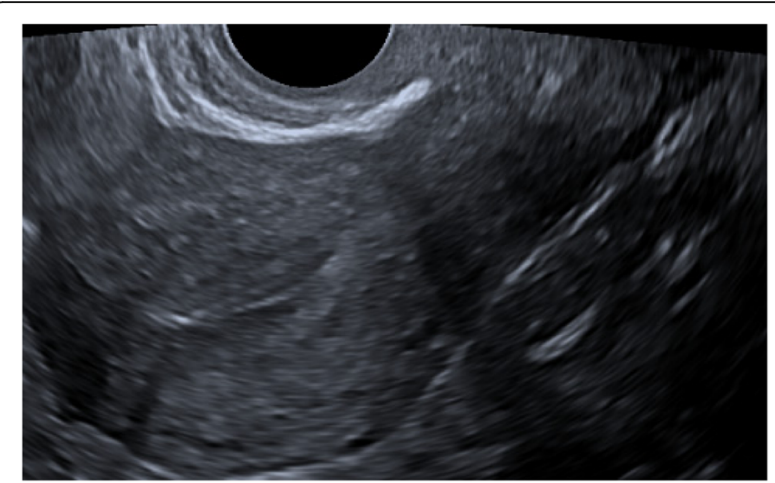

Fig. 4 Sagittal view by TVUS showing thickened echogenic endometrium, measuring about $11.5 \mathrm{~mm}$ in maximal anteroposterior diameter with regular endometrial outline and heterogenous echo pattern with multiple echogenic areas seen scattered through myometrium (enlarged glands). Histopatholgy result of the endometrial biopsy was consistent with adenomyosis

of subendometrial halo; we suspected her to have endometrial carcinoma, which is proven by the histopathology. In another patient, it was hyperechoic homogenous thickened endometrium $25 \mathrm{~mm}$ showing slightly indistinct borders; we suggested it was endometrial hyperplasia, but with histopathology, it was endometrial carcinoma (Fig. 7).

So we detected that the sensitivity of TVUS to accurately detect endometrial pathology in comparison to histopathology results was about $92.9 \%$ as there were two patients misdiagnosed as endometrial carcinoma and endometrial hyperplasia by TVUS, which were diagnosed after histopathology as endometrial cystic atrophy and endometrial carcinoma, respectively; the specificity of TVUS to accurately detect no abnormality and normal scan by follow-up was 100\%, with $96 \%$ accuracy value, $100 \%$ positive predictive value (PPV), and $91.7 \%$ negative predictive value (NPV).

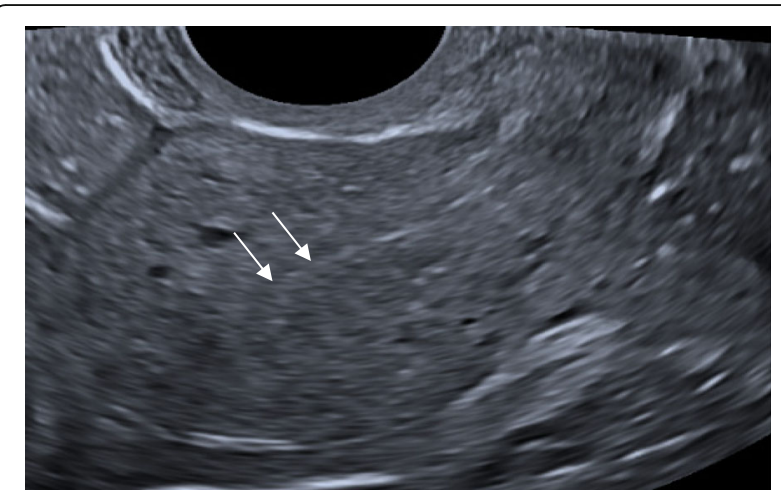

Fig. 5 Sagittal view by TVUS showing a thin echogenic line (white arrow), $3 \mathrm{~mm}$ surrounded by hypoechoic halo. Histopathology result of the endometrial biopsy was consistent with endometrial atrophy

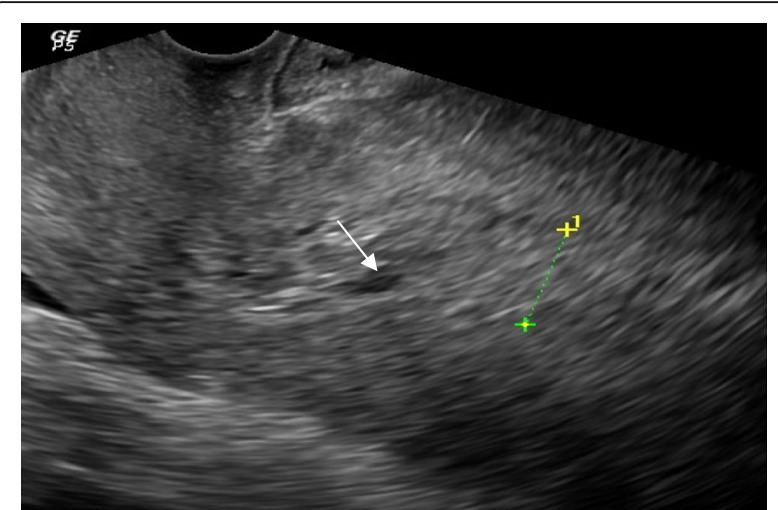

Fig. 6 Sagittal view by TVUS showing thickened echogenic endometrium and heterogeneous echo pattern measuring about $14.7 \mathrm{~mm}$ in maximal anteroposterior diameter, showing variable sized cystic hypoechoic areas (white arrow) and preserved subendometrial halo. Histopathology result of the endometrial biopsy was consistent with endometrial cystic atrophy

\section{Associations}

The associations are as follows:

1- Association between the presence of abnormality (pathology) in TVUS and age, duration of hormonal therapy, presence of atypical vaginal bleeding, and endometrial appearance by TVUS (Table 3 )

2- Association between the age of patients and presence of pathology by TVUS

The age of patients with no pathology detected in them ranged from 32 to 55 years old with a mean age of 43.23 years and standard deviation of \pm 6.20 years.

The age of patients with pathology detected in them ranged from 37 to 55 years old with a mean age of 46.21 years and standard deviation \pm 5.21 years.

The $p$ value detected for the relation between age and presence of side effects of tamoxifen was 0.070 , showing

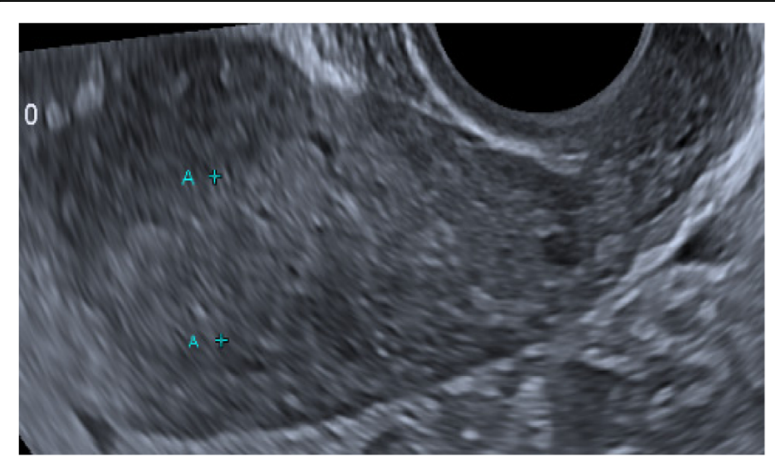

Fig. 7 Sagittal view by TVUS showing a thickened endometrium measuring about $30 \mathrm{~mm}$ in maximal anteroposterior diameter, heterogenous echo pattern, and multiple hypoechoic areas with indistinct borders. Histopathology result of the endometrial biopsy was consistent with endometrial carcinoma 
Table 3 Presence of pathology with different variables

\begin{tabular}{|c|c|c|c|c|c|c|}
\hline & & Negative pathology (no. = 22) & Positive pathology (no. = 28) & Test value & $p$ value & Sig \\
\hline \multirow[t]{2}{*}{ Age (years) } & Mean \pm SD & $43.23 \pm 6.20$ & $46.21 \pm 5.21$ & $-1.851 \cdot$ & 0.070 & NS \\
\hline & Range & $32-55$ & $37-55$ & & & \\
\hline \multirow[t]{2}{*}{ Hormonal therapy duration (year) } & Mean \pm SD & $1.86 \pm 1.18$ & $2.79 \pm 1.48$ & -2.435 & 0.019 & S \\
\hline & Range & $0.33-5$ & $0.75-5$ & & & \\
\hline \multirow[t]{2}{*}{ Atypicalvaginal bleeding } & No & $22(100.0 \%)$ & 19 (67.9\%) & $8.624^{*}$ & 0.003 & $\mathrm{HS}$ \\
\hline & Yes & $0(0.0 \%)$ & $9(32.1 \%)$ & & & \\
\hline \multirow[t]{2}{*}{ US-endo. thickness (mm) } & Mean \pm SD & $6.45 \pm 1.52$ & $13.19 \pm 6.14$ & -5.023 & 0.000 & $\mathrm{HS}$ \\
\hline & Range & $3-8$ & $3-30$ & & & \\
\hline \multirow[t]{2}{*}{ US-endo. regular } & No & $0(0.0 \%)$ & $10(35.7 \%)$ & $9.821^{*}$ & 0.002 & HS \\
\hline & Yes & 22 (100.0\%) & 18 (64.3\%) & & & \\
\hline
\end{tabular}

$p$ value $>0.05$ : non-significant (NS), $p$ value $<0.05$ : significant (S), $p$ value $<0.01$ : highly significant (HS)

${ }^{*}$ Chi-square test

-Independent $t$ test

that there was no significant relation between the age of patient and presence of pathology as side effects from tamoxifen.

3- Association between duration of tamoxifen therapy and presence of pathology in TVUS

Twenty-two patients (44\%) with period of treatment with tamoxifen ranging from 3 months up to 5 years, mean 1.86 years and standard deviation \pm 1.18 years, had no side effects from it.

Twenty-eight patients (56\%) with period of tamoxifen treatment ranging from 7 months up to 5 years, mean 2.67 and standard deviation \pm 1.41 , and had side effects from it.

The $p$ value detected for the relation between period of tamoxifen use that would lead to occurrence of side effects was 0.035 showing that there is a significant relation between duration of therapy and occurrence of side effects.

4- Association between synchronization of presence of atypical vaginal bleeding with underlying pathology in TVUS

Nine patients of 28 (32.1\%) were complaining from abnormal vaginal bleeding of various grades.

The $p$ value detected for the relation between presence of abnormal vaginal bleeding with underlying pathology was 0.011 showing that there is a significant relation between them.

5- Association between appearance of abnormal vaginal bleeding with duration of tamoxifen therapy and endometrial thickness (Table 4)

There is no significant relation between the appearance of symptoms and duration of tamoxifen therapy, but there is a highly significant relation between increased endometrial thickness and appearance of abnormal vaginal bleeding.

6- Association between the presence of adnexal lesion and age of patients, duration of hormonal therapy and endometrial thickness (Table 5)

There is no significant relation between the appearance of adnexal cysts either simple or complicated and age of patients, and duration of tamoxifen therapy and endometrial thickness as their endometrial thickness ranged from 5 to $7.7 \mathrm{~mm}$ with a mean of $6.23 \mathrm{~mm}$ and $\mathrm{SD}$ of \pm 1.21 .

7- Association between histopathology results of endometrial pathology and different variables (Table 6)

Table 4 Presence of symptoms with different variables

\begin{tabular}{|c|c|c|c|c|c|c|}
\hline & & \multicolumn{2}{|c|}{ Symptomatic (vaginal bleeding) } & \multirow{2}{*}{$\begin{array}{l}\text { Test } \\
\text { value. }\end{array}$} & \multirow{2}{*}{$\begin{array}{l}p \\
\text { value }\end{array}$} & \multirow[t]{2}{*}{ Sig } \\
\hline & & No & Yes & & & \\
\hline \multirow[t]{2}{*}{ Hormonal (year) } & Mean $\pm S D$ & $2.28 \pm 1.42$ & $2.56 \pm 1.1$ & -0.537 & 0.594 & NS \\
\hline & Range & $0.33-5$ & $1-5$ & & & \\
\hline \multirow[t]{2}{*}{ US-endo. thickness (mm) } & Mean $\pm S D$ & $9.09 \pm 4.26$ & $15.39 \pm 8.71$ & -3.252 & 0.002 & $\mathrm{HS}$ \\
\hline & Range & $3-18.5$ & $3-30$ & & & \\
\hline
\end{tabular}


Table 5 Adnexal cysts with different variables

\begin{tabular}{|c|c|c|c|c|c|c|}
\hline & & Complicated cyst (no. $=2$ ) & Simple cyst (no. $=2$ ) & Test value & $p$ value & Sig \\
\hline \multirow[t]{2}{*}{ Age (years) } & Mean \pm SD & $43.00 \pm 2.83$ & $44.50 \pm 4.95$ & 0.372 & 0.746 & NS \\
\hline & Range & $41-45$ & $41-48$ & & & \\
\hline \multirow[t]{2}{*}{ Endometrial thickness } & Mean \pm SD & $7.2 \pm 0.71$ & $5.25 \pm 0.35$ & -3.484 & 0.073 & NS \\
\hline & Range & $6.7-7.7$ & $5-5.5$ & & & \\
\hline \multirow[t]{2}{*}{ Hormonal (year) } & Mean \pm SD & $2.88 \pm 3.01$ & $3.00 \pm 2.83$ & 0.043 & 0.970 & NS \\
\hline & Range & $0.75-5$ & $1-5$ & & & \\
\hline
\end{tabular}

-Independent $t$ test

\section{Discussion}

Hormonal therapy is widely utilized as an adjuvant therapy in women diagnosed with breast cancer; in those patients, despite its positive risk/benefit ratio, it may cause secondary effects on the endometrium, including endometrial atrophy, endometrial polyp, endometrial hyperplasia, and endometrial carcinoma. Our study aims to determine the role of TVUS in the detection of endometrial changes.

In our study, there were 9 patients (18\%) presented with abnormal vaginal bleeding (symptomatic) with period of tamoxifen use ranging from 2 to 5 years and 41 patients (82\%) came for annual screening (asymptomatic) with period of therapy ranging from 3 months up to 5 years which was higher than Kochar et al. [4] who conducted a study in which $34 \%$ of the patients were symptomatic as compared to $66 \%$ who were asymptomatic, yet Gerber et al. [5] had up to $72.2 \%$ asymptomatic patients in their study.

Cohen et al. [6] showed that $28.6 \%$ of patients on tamoxifen had endometrial pathology and the incidence was significantly more in symptomatic patients, yet in our study, we had 24 patients (85.7\%) with different endometrial abnormalities.

In our study, 24 patients (46\%) had thickened endometrium with endometrial thickness ranging from 8 to $30 \mathrm{~mm}$ which is matched with Kedar et al. [7] who performed ultrasonography on 111 asymptomatic postmenopausal women with breast cancer who were randomly assigned to receive tamoxifen, $20 \mathrm{mg} /$ day, or placebo; the endometrial lining was greater than $5 \mathrm{~mm}$ (mean, $9.1 \mathrm{~mm}$ ) in 49\%, while Cecchini et al. [8] in a study of 72 asymptomatic, postmenopausal patients with breast cancer who received tamoxifen, 20 to $30 \mathrm{mg} / \mathrm{day}$, for 21 months reported an endometrial thickness greater than $5 \mathrm{~mm}$ in 71 of 72 patients on vaginal ultrasonography. Also, Cohen et al. [6] did annual ultrasonography screening of 737 postmenopausal patients with breast cancer receiving tamoxifen, $20 \mathrm{mg} /$ day, for a median duration of 50 months, which showed an endometrial thickness greater than $6 \mathrm{~mm}$ in 209 patients (28\%).

In our study, 24 patients (46\%) with thickened endometrium (8 to $30 \mathrm{~mm}$ ) showed different types of pathology in endometrium as adenomyosis, polyp, atrophy, hyperplasia, and carcinoma (according to $\mathrm{D} \& \mathrm{C}$ and histopathology results); these results matched with Kedar et al. [7] who performed ultrasonography on 111 asymptomatic postmenopausal women with breast cancer who were randomly assigned to receive tamoxifen, $20 \mathrm{mg} /$ day, or placebo. Among women receiving tamoxifen, the thickness of the endometrial lining was greater than $5 \mathrm{~mm}$ (mean, $9.1 \mathrm{~mm}$ ) in $49 \%$; the mean thickness for women receiving placebo was $4.8 \mathrm{~mm}$, yet Cecchini et al. [8] in a study of 72 asymptomatic,

Table 6 Type of pathology with different variables

\begin{tabular}{|c|c|c|c|c|c|c|c|c|c|}
\hline & & $\begin{array}{l}\text { Polyp } \\
(\text { no. = 7) }\end{array}$ & $\begin{array}{l}\text { Atrophy } \\
(\text { no. }=3)\end{array}$ & $\begin{array}{l}\text { Hyperplasia } \\
\text { (no. =7) }\end{array}$ & $\begin{array}{l}\text { Carcinoma } \\
\text { (no. = 2) }\end{array}$ & $\begin{array}{l}\text { Adenomyosis } \\
\text { (no. = 5) }\end{array}$ & Test value & $p$ value & Sig. \\
\hline \multirow[t]{2}{*}{ Age (years) } & Mean \pm SD & $47.83 \pm 4.40$ & $44.00 \pm 1.41$ & $49.71 \pm 3.90$ & $52.50 \pm 2.12$ & $42.40 \pm 5.32$ & 3.290 & 0.036 & S \\
\hline & Range & $40-52$ & $43-45$ & $45-55$ & $51-54$ & $37-50$ & & & \\
\hline \multirow[t]{2}{*}{ Hormonal (year) } & Mean \pm SD & $3.64 \pm 1.65$ & $2.33 \pm 0.58$ & $2.79 \pm 0.70$ & $3.75 \pm 1.77$ & $1.40 \pm 0.42$ & 3.438 & 0.028 & S \\
\hline & Range & $1-5$ & $2-3$ & $2-4$ & $2.5-5$ & $1-2$ & & & \\
\hline \multirow[t]{2}{*}{ Atypical vaginal bleeding } & No & $4(57.14 \%)$ & $0(0.0 \%)$ & $6(85.71 \%)$ & $0(0.0 \%)$ & $5(100 \%)$ & 13.029 & 0.011 & S \\
\hline & Yes & $3(42.85 \%)$ & $3(100 \%)$ & $1(14.29 \%)$ & $2(100.0 \%)$ & $0(0.0 \%)$ & & & \\
\hline \multirow[t]{2}{*}{ US-endo. thickness (mm) } & Mean \pm SD & $14.64 \pm 1.49$ & $7.0 \pm 6.08$ & $16.71 \pm 2.20$ & $27.50 \pm 3.54$ & $9.76 \pm 1.00$ & 23.356 & 0.000 & HS \\
\hline & Range & $13-17$ & $3-14$ & $12.5-19$ & $25-30$ & $8.60-11$ & & & \\
\hline \multirow[t]{2}{*}{ US-endo. regular } & No & $0(00 \%)$ & $3(100 \%)$ & $0(0.0 \%)$ & $2(100.0 \%)$ & $5(100 \%)$ & 6.507 & 0.164 & NS \\
\hline & Yes & $7(100.0 \%)$ & $0(0.0 \%)$ & 7 (100.0\%) & $0(0.0 \%)$ & 0 (0.0\%) & & & \\
\hline
\end{tabular}


postmenopausal patients with breast cancer who received tamoxifen, 20 to $30 \mathrm{mg} /$ day, for 21 months reported an endometrial thickness greater than $5 \mathrm{~mm}$ in 71 of 72 patients on vaginal ultrasonography. Cohen et al. [6] did annual ultrasonography screening of 737 postmenopausal patients with breast cancer receiving tamoxifen, $20 \mathrm{mg} /$ day, for a median duration of 50 months, which showed an endometrial thickness greater than 6 $\mathrm{mm}$ in 209 patients (28\%).

Our study stated that TVUS had $92.2 \%$ sensitivity, $100 \%$ specificity, $96 \%$ accuracy in detecting endometrial lesions, 100\% positive predictive value (PPV), and 91.7\% negative predictive value (NPV). This was matching with Cohen et al. [6] and Pepper et al. [9] who found sensitivity of $91-100 \%$, specificity of $96 \%$, positive predictive value of $26.32 \%$, and negative predictive of $100 \%$ of TVUS in detecting endometrial pathologies

In our study, we detected that there is a significant risk of premalignant and malignant lesions of endometrium in patients on long-term tamoxifen use, but we could not arrive to a statistically significant relation that the duration of tamoxifen therapy could affect the type of pathology that appears due to our limitation of sample size and follow-up duration; however, increase duration increases the incidence of malignancy. So, we recommend that all patients on long-term tamoxifen use should be annually screened for endometrial pathology.

Ozsener et al. [10] have shown that tamoxifen use increases the risk of endometrial cancer and premalignant change. They also noticed significant relation between endometrial thickness and duration of tamoxifen treatment. Hann et al. [11] found abnormal endometrial biopsy in $44 \%$ of women treated with tamoxifen for less than 5 years whereas $58 \%$ of endometrial biopsies revealed abnormal results when the duration of tamoxifen treatment was $>5$ years.

Jindal et al. [2] has shown one case of endometrial carcinoma and five patients of endometrial hyperplasia with nuclear atypia. This shows significant risk of premalignant and malignant change in patients on long-term tamoxifen.

Peters-Engl et al. [12] demonstrated that clinical benefits of tamoxifen greatly outweigh the risk. They recommended annual follow-up of patients on tamoxifen. Cohen et al. [6] showed that $28.6 \%$ of patients on tamoxifen had endometrial pathology. The incidence was significantly more in symptomatic patients.

Seoud et al. [13] concluded that the value of routine screening for endometrial pathology in patients on tamoxifen is controversial. They found that all patients who developed an abnormal endometrium had abnormal vaginal bleeding. Bernstein et al. [14] in a case control study concluded that endometrial cancer is associated with tamoxifen use and the risk is increased with the duration of tamoxifen use. In a meta-analysis, MacMahon et al. [15] concluded that an association exists between endometrial cancer and tamoxifen use.

\section{Conclusion}

The need for endometrial surveillance by TVUS in breast cancer patients undergoing adjuvant treatment with tamoxifen is of importance for the detection of endometrial abnormalities. Such a screening procedure is important in an attempt to detect endometrial cancers earlier as those patients worry a great deal about developing a second cancer.

In our study, we believe that TVUS is a sensitive and rather specific method to evaluate the endometrial lesions, but often this modality does not provide the physician with sufficient diagnostic information. So we need endometrial biopsies in those patients with positive TVUS findings due to higher sensitivities, specificities, and positive and negative predictive values for evaluating breast cancer patients taking tamoxifen.

\section{Abbreviations}

TVUS: Transvaginal ultrasonography

\section{Acknowledgements}

Not applicable.

\section{Authors' contributions}

$\mathrm{WH}$ made the design of the work. AS contributed to the revision of data. MR participated in the design of the study and interpretation of data, and did the sonography for the cases. AS contributed to the acquisition and analysis of data and drafted the manuscript. All authors read and approved the final manuscript.

\section{Funding}

No funding was obtained for this study.

Availability of data and materials

Data sharing is not applicable to this article as no datasets were generated or analyzed during the current study.

Ethics approval and consent to participate

The study was done after the approval of the ethical board of Ain Shams University and Helwan University; an informed written consent was taken from each participant in the study.

Consent for publication

Written consent for publication was taken from all participants.

\section{Competing interests}

The authors declare that they have no competing interests

\section{Author details}

'Department of Radio-diagnosis, Faculty of Medicine, Ain Shams University, Ramsis St., Abbasia, Cairo, Egypt. ²Department of Radio-diagnosis, Faculty of Medicine, Helwan University, Cairo, Egypt.

Received: 22 June 2019 Accepted: 22 July 2019

Published online: 06 September 2019

\section{References}

1. Lee S, Kim YH, Kim SC, Joo JK, Seo DS, Kim KH, Lee KS (2018) The effect of tamoxifen therapy on the endometrium and ovarian cyst formation in patients with breast cancer. Obstet Gynecol Sci 61(5):615-620 
2. Jindal A, Mohi MK, Kaur M, Kaur B, Singla R, Singh S (2015) Endometrial evaluation by ultrasonography, hysteroscopy and histopathology in cases of breast carcinoma on tamoxifen therapy. J Mid Life Health. 6(2):59

3. Sahdev A (2007) Imaging the endometrium in postmenopausal bleeding. BMJ. 334(7594):635-636

4. Kochar SP, Arora P, Chattopadhyay AB (2005) Tamoxifen therapy for breast cancer and endometrial pathology. Med J Armed Forces India 61:313-315

5. Gerber B, Krause A, Müller H, Reimer T, Külz T, Makovitzky J, Kundt G, Friese $K$ (2000) Effects of adjuvant tamoxifen on the endometrium in postmenopausal women with breast cancer: a prospective long-term study using transvaginal ultrasound. J Clin Oncol 18(20):3464-3470

6. Cohen I, Azaria R, Shapira J, Yigael D, Tepper R (2012) Significance of secondary ultrasonographic endometrial thickening in postmenopausal tamoxifen-treated women. Cancer 94:256-266

7. Kedar RP, Bourne TH, Powles TJ, Collins WP, Ashley SE, Cosgrove DO et a (1994) Effects of tamoxifen on the uterus and ovaries of postmenopausal women in a randomized breast cancer prevention trial. Lancet 343:1318-1321

8. Cecchini S, Ciatto S, Bonardi R, Mazzotta A, Grazzini G, Pacini P et al (1996) Screening by ultrasonography for endometrialcarcinoma in postmenopausal breast cancer patients under adjuvant tamoxifen. Gynecol Oncol 60:409-411

9. Pepper JM, Oyesanya OA, Dewart PJ, Howell A, Seif MW (1996) Indices of differential endometrial: myometrial growth may be used to improve the reliability of detecting endometrial neoplasia in women on tamoxifen. Ultrasound Obstet Gynecol 8:408-411

10. Ozsener S, Itil I, Dikmen Y (1998) Endometrial pathology of 104 postmenopausal breast cancer patients treated with tamoxifen. Eur J Gynaecol Oncol 19(6):580-583

11. Hann LE, Gretz EM, Bach AM, Francis SM (2001) Sonohysterography for evaluation of the endometrium in women treated with tamoxifen. Am J Roentgenol 177(2):337-342

12. Peters-Engl C, Frank W, Danmayr E, Friedl HP, Leodolter S, Medl M (1999) Association between endometrial cancer and tamoxifen treatment of breast cancer. Breast Cancer Res Treat 54:255-260

13. Seoud M, Shamseddine A, Khalil A, Salem Z, Saghir N, Bikhazi K et al (1999) Tamoxifen and endometrial pathologies: a prospective study. Gynaecol Oncol 75:15-19

14. Bernstein L, Deapen D, Cerhan JR, Schwartz SM, Liff J, McGann-Maloney E et al (1999) Tamoxifen therapy for breast cancer and endometrial cancer risk. J Natl Cancer Inst 91:1654-1662

15. MacMahon B (1997) Overview of studies on endometrial cancer and other types of cancer in humans: Perspectives of an epidemiologist. Semin Oncol 24:S1-122-SS1-39

\section{Publisher's Note}

Springer Nature remains neutral with regard to jurisdictional claims in published maps and institutional affiliations.

\section{Submit your manuscript to a SpringerOpen ${ }^{\circ}$ journal and benefit from:}

- Convenient online submission

- Rigorous peer review

- Open access: articles freely available online

- High visibility within the field

- Retaining the copyright to your article

Submit your next manuscript at $\boldsymbol{\nabla}$ springeropen.com 